\title{
Association between mixture of persistent organic pollutants and thyroid pathologies in a Belgian population
}

\author{
Patrice Dufour $^{\mathrm{a}, \mathrm{b}, *}$, Catherine Pirard ${ }^{\mathrm{a}, \mathrm{b}}$, Patrick Petrossians ${ }^{\mathrm{c}}$, Albert Beckers ${ }^{\mathrm{c}}$, Corinne Charlier ${ }^{\mathrm{a}, \mathrm{b}}$ \\ ${ }^{a}$ Laboratory of Clinical, Forensic and Environmental Toxicology, University of Liege (ULg), CHU (B35), 4000, Liege, Belgium \\ ${ }^{\mathrm{b}}$ Center for Interdisciplinary Research on Medicines (C.I.R.M.), University of Liege (ULg), CHU (B35), 4000, Liege, Belgium \\ ${ }^{\mathrm{c}}$ Department of Endocrinology, University of Liege (ULg), CHU (BE 035), 4000, Liege, Belgium
}

\section{A R T I C L E I N F O}

\section{Keywords:}

Hyperthyroidism

Hypothyroidism

Endocrine disruptors

Persistent organic pollutants

Mixture effect

\begin{abstract}
A B S T R A C T
Previous years, the incidence of autoimmune thyroid diseases has increased worldwide. The presence of many pollutants in the environment suspected to be thyroid disruptors may have contributed to the observed increase. Unfortunately, the results from epidemiological studies assessing the association between pollution and thyroid disorders remain inconsistent, maybe due to a nearly complete neglect of the mixture effect. The blood levels of 12 brominated flame retardants, 3 polychlorinated biphenyls, 16 organochlorine pesticides, 7 perfluoroalkyl substances and 16 phenolic organohalogens were measured in 35 hypothyroid and 44 hyperthyroid volunteers and in 160 individuals from the general population designed as controls. Weighted quantile sum (WQS) regressions were performed to compute indexes representing the mixture of POPs, and we assessed the relations with thyroid disorders. Nineteen pollutants were detected in more than $40 \%$ of the individuals and were thus included in the WQS indexes. The WQS index was statistically significantly associated with an increased odds of hypothyroidism (odds ratio $(\mathrm{OR})=98.1$; 95\% CI: 5.51-1747) with the highest weights attributed to PCB 138 $(\mathrm{w}=0.210), 3-\mathrm{OH}-\mathrm{CB} 180(\mathrm{w}=0.197), 4-\mathrm{OH}-\mathrm{CB} 146(\mathrm{w}=0.188), 4$, 4-DDE $(\mathrm{w}=0.156)$ while there were no evidence of a relation with increased odds of hyperthyroidism. Given the relative low number of individuals included in the present investigation, standard WQS methodology could not be used, this study should thus be considered as a preliminary, hypothesis-generating study. Nevertheless, these results highlighted the importance of considering the potential effect of chemical mixture when studying endocrine disruptors.
\end{abstract}

\section{Introduction}

Diseases affecting the thyroid are among the most common endocrine pathologies. In area where the iodine intake is sufficient (most of the European countries are considered as iodine-sufficient area), autoimmunity is the most common etiology for thyroid disorders (Lind et al., 1998; Garmendia Madariaga et al., 2014). Hashimoto's disease or autoimmune hypothyroidism is characterized by an autoimmune destruction of the thyroid follicles leading to a decreased production and secretion of the thyroid hormones (THs). In Graves' disease or autoimmune hyperthyroidism, the antibodies are directed against the thyroid stimulating hormone (TSH) receptor. These antibodies stimulate the receptor, which leads to a continuous activation of the thyrocytes and a higher level of production and secretion of TH (Benvenga et al., 2015; McGrogan et al., 2008; McLeod and Cooper, 2012). The incidence of these pathologies has been rising and this increase is probably the consequence of environmental factors such as smoking or nutritional habits (Leese et al., 2008; McLeod and Cooper, 2012; Rizzo et al., 2010). Several epidemiological studies also highlighted that the risk to present thyroid diseases or thyroid autoantibodies is higher for individuals exposed to high levels of environmental pollutants (Chevrier et al., 2010; Langer et al., 2007; Melzer et al., 2010; Oulhote et al., 2016; Schell et al., 2009; Turyk et al., 2008). Nevertheless, these associations are not firmly established since some authors have found no correlation between pollutant exposure and the thyroid disease incidence (Benson et al., 2018; Chan et al., 2011; Donato et al., 2008; Yard et al., 2011). However, the discrepancies may be explained by several factors, among them, the paucity of validated statistical methodology to evaluate the risks of chemical mixture.

Most toxicological researches and in particular the research on endocrine disruptors have been focused on single chemical effects (Kortenkamp, 2007; Kortenkamp and Faust, 2018; Martin et al., 2013). However, a growing number of investigations showed that the effects of mixture components can be additive, and that each component

\footnotetext{
* Corresponding author. CHU (B35) University of Liege, 1, Avenue de l'Hôpital, 4000, Liège, Belgium.

E-mail address: pdufour@uliege.be (P. Dufour).
} 
contributes to the combination effect in relation to its dose and its potency. An important consequence of this observation is the "something from nothing" phenomenon: the combination of a sufficient number of chemicals at individual concentrations associated with zero effect will jointly produce an observable effect (Kortenkamp, 2014; Faust et al., 2001; Hermens et al., 1985; Silva et al., 2002; Hass et al., 2007; Villa et al., 2012). Many chemicals which largely have contaminated the environment and the human populations are suspected to be thyroid disruptors (Boas et al., 2012), among them, the persistent organic pollutants (POPs) such as polychlorinated biphenyls (PCBs), brominated flame retardants (BFRs), organochlorine pesticides, perfluoroalkyl substances (PFASs) or phenolic organohalogens (POHs). Moreover, the effects of these thyroid disruptor have been demonstrated to be additive or even synergic (Chen et al., 2016; Crofton et al., 2005; Miller et al., 2012) in laboratory studies on rats. A better assessment of the effects associated with mixtures of thyroid disruptors at the human population scale is thus necessary to clarify the potential associations between the rise of thyroid pathology cases and the exposure to environmental pollutants.

However, several issues arise when one tries to assess health effects of xenobiotics mixture: standard multiple regression models which include multiple pollutants are not suitable for these analyses, because to include a large number of pollutants into regression leads to models with instable coefficient estimates and reduced statistical power. Moreover, many chemicals present in the environment are highly intercorrelated making difficult the identification of the pollutant really responsible for the effect usually observed with a classical multivariate regression model (Billionnet et al., 2012). Advanced statistical methodologies are thus required. To the best of our knowledge, only Berg et al. (2017) applied such methodologies to assess the relations between a mixture of POPs and the thyroid function at a human population scale. In order to avoid multicollinearity issues and to reduce the dimensionality of the statistical models, they performed partial least regression, principal component analysis and hierarchical clustering. These methods allowed assessing the associations between concentrations of PCBs and PFASs and the thyroid hormone levels in the blood of Swedish pregnant women. Nevertheless, these reduction methods were unable to identify the pollutants effectively associated with the health outcome. A recent method called weighted quantile sum (WQS) regression developed by Gennings et al. (2010) and improved by Carrico et al. (2015) demonstrated its capability to overcome collinearity issues and to provide parsimonious and more accurate statistical models while allowing the identification of the "bad actors".

In the present work, we applied the WQS regression to assess the relations between the concentrations of 12 BFRs, 3 PCBs, 16 organochlorine pesticides, 7 PFASs and 16 POHs measured in the serum and the risk of presenting autoimmune thyroid pathology in a Belgian population.

\section{Materials and methods}

\subsection{Study participants}

This case-control study was focused on patients diagnosed for autoimmune thyroid pathologies. In collaboration with the department of Endocrinology of the University Hospital of Liege (Belgium), we recruited 35 individuals suffering from Hashimoto's hypothyroidism and 44 patients suffering from Graves' hyperthyroidism. The recruitment took place from February 2015 to November 2018. The other inclusion criteria were (1) to live in Belgium for at least 10 years and (2) to have been diagnosed less than 2 years ago. In 2015, 252 individuals from the general population living in the Province of Liege were recruited in collaboration with the Office of the Province of Liege (Pirard et al., 2018 ) and some additional participants $(n=15)$ were newly recruited in November 2018. Among these participants, 70 were randomly designed as controls for cases of hypothyroidism and 90 for cases of hyperthyroidism (so that there are 2 controls for one case), controls had to be frequency matched to cases by sex and age (within 5 years groups). All the volunteers signed an informed consent and provided a blood sample in clot activator tubes without gel. A questionnaire was also administered. The blood samples were stored at $4{ }^{\circ} \mathrm{C}$ before their transfer to the Toxicology lab (within the day), and were then centrifuged at $3000 \mathrm{rpm}$ for $5 \mathrm{~min}$ to collect the serum fractions which were stored at $-20{ }^{\circ} \mathrm{C}$.

\subsection{POPs analyses}

\subsubsection{Organochlorine pesticides and PCBs}

Organochlorine pesticides (namely, $\alpha$-, $\beta$-, $\gamma$-hexachlorohexane ( $\mathrm{HCH})$, hexachlorobenzene (HCB), aldrine, endrine, dieldrine, oxychlordane, trans-heptachlor epoxide, trans-chlordane, trans- and cisnonachlor, 2,4'- and 4,4'-dichlorodiphenyldichloroethylene (DDE), 2,4'-dichlorodiphenyltrichloroethane (DDT) and $\beta$-endosulfan) and PCBs (namely PCB 138, -153, - 180) were analyzed according the method described in Pirard et al. (2018). Briefly, $500 \mu \mathrm{L}$ of serum sample denatured with acetonitrile were extracted twice with $5 \mathrm{~mL}$ of a hexane/acetone mixture $(90 / 10, v / v)$. The organic phase was purified on a Bond Elut Certify cartridge (Agilent technologies) and then evaporated till $500 \mu \mathrm{L}$. The residual volume was transferred to a GC vial containing $50 \mu \mathrm{L}$ of nonane as keeper and let slowly evaporated at room temperature. The extracts were then analyzed on an Agilent 7890 A GC coupled with an Agilent 7000 A triple quad mass spectrometer (MS) operating in electron capture negative ionization mode. The separation took place on a $30 \mathrm{~m}$ SGE HT8 column (Agilent technologies).

\subsubsection{BFRs}

The method employed to determinate BFRs (namely, polybrominated diphenylethers (PBDE) $-47,-99,-100,-153,-154$, -183 and 209, polybromobiphenyl 153 (PBB 153), hexabromobenzene (HBBz), pentabromoethylbenzene (PBEB), 2-ethylhexy-2,3,4,5-tetrabromobenzoate (ЕHTBB) and 1,2-bis(2,4,6-tribromophenoxy) ethane (BTBPE)) in serum was developed and validated by Pirard and Charlier (2018). Briefly, $1 \mathrm{~mL}$ of serum sample was denatured with glacial acetic acid before being extracted twice with $4 \mathrm{~mL}$ of a hexane/acetone mixture $(95 / 5, v / v)$. Organic phase were evaporated till $500 \mu \mathrm{L}$ and then purified on a PHREE cartridge (Phenomenex). The eluate was transferred to a GC vial containing $50 \mu \mathrm{L}$ of nonane as keeper and let slowly evaporated at room temperature. The chromatographic analysis was performed on an Agilent 7890 A GC/7000 A triple quad MS operating in electron capture negative ionization mode and equipped with a 15 m Rtx-1614 column (Restek).

\subsection{3. $\mathrm{POHs}$}

The analytical procedure used for the determination of $\mathrm{POHs}$ (namely, pentachlorophenol (PCP), tetrabromobisphenol A (TBBPA), 2,4,6-tribromophenol (2,4,6-TBP), 2,3,6-tribromophenol (2,3,6-TBP), 2,4,5-tribromophenol (2,4,5-TBP), 2,3,4,6-tetrabromophenol (2,3,4,6TeBP) 6-hydroxy-polybromodiphenylether 47 (6-OH-BDE 47), 5-hydroxy-polybromodiphenylether 47 (5-OH-BDE 47), 5'-hydroxy-polybromodiphenylether 99 (5'-OH-BDE 99), 4-hydroxy-polychlorinated biphenyl 107 (4-OH-CB 107), 3-hydroxy-polychlorinated biphenyl 138 (4-OH-CB 138), 4-hydroxy-polychlorinated biphenyl 146 (4-OH-CB 146), 3-hydroxy-polychlorinated biphenyl 153 (3-OH-СB 153), 4-hydroxy-polychlorinated biphenyl 172 (4-OH-CB 172), 3-hydroxy-polychlorinated biphenyl 180 (3-OH-CB 180) and 4-hydroxy-polychlorinated biphenyl 187 (4-OH-CB 187)) has been described in Dufour et al. (2016). In summary, $1 \mathrm{~mL}$ of serum sample was denatured with $3 \mathrm{~mL}$ of a water/formic acid/2-propanol mixture (50/40/10, v/v). The sample was next loaded and purified on an Oasis MAX SPE cartridge (Waters) and eluted with $5 \mathrm{~mL}$ of methanol/formic acid mixture (98/2, $\mathrm{v} / \mathrm{v})$. The volume of the eluate was reduced by evaporation to approximately $1 \mathrm{~mL}$ and then extracted with $5 \mathrm{~mL}$ hexane. The organic 
phase was evaporated to dryness and the residue was reconstituted with dichloromethane and methanol. The extract was then derivatized with trimethylsilyldiazomethane during $30 \mathrm{~min}$ at $40{ }^{\circ} \mathrm{C}$. The derivatized extract is then evaporated to dryness, reconstituted in $70 \mu \mathrm{L}$ of isooctane and finally transferred to a GC vial. An Agilent 7890 A GC/ 7000 A triple quad MS operating in electron capture negative ionization mode and equipped with a $30 \mathrm{~m}$ HP-5MS column (Agilent) was used for the final analysis.

\subsubsection{PFASs}

We measured the concentrations of PFASs (namely, perfluorooctane sulfonate (PFOS), perfluorohexane sulfonate (PFHxS), perfluorooctanoic acid (PFOA), perfluorononanoic acid (PFNA), perfluorodecanoic acid (PFDA), perfluoroundecanoic acid (PFUdA) and perfluoroheptanoic acid (PFHpA)) in serum by employing the method of Kärrman et al. (2007) slightly modified as detailed in Dufour et al. (2018). Shortly, $1 \mathrm{~mL}$ of serum was denatured with acid formic. Next, the sample was loaded and purified on an Oasis WAX SPE cartridge (Waters) and eluted with $2 \times 2 \mathrm{~mL}$ of ammonium hydroxide $2 \%$ in methanol. The eluate was evaporated to dryness and reconstituted in $80 \mu \mathrm{L}$ of a $2 \mathrm{mM}$ ammonium acetate in acetonitrile/2 $\mathrm{mM}$ ammonium acetate in water mixture $(20 / 80, \mathrm{v} / \mathrm{v})$. The analytical separation was performed using an Acquity Ultra Performance UHPLC (Waters) equipped with a Kinetex F5 Core-Shell column (Phenomenex) and operating in gradient mode with $2 \mathrm{mM}$ ammonium acetate in acetonitrile and $2 \mathrm{mM}$ ammonium acetate in water mobile phases. A Quattro Premier XE mass spectrometer coupled to the UHPLC was used for the final determination, the mass spectrometer operating in negative electrospray ionization and MRM mode.

\subsubsection{Total serum lipids}

Total cholesterol and triglycerides were measured in serum on a Cobas 8000 modular analyzer system (Roche/Hitachi, Switzerland) by enzymatic colorimetric tests using dedicated Roche's kits. The total lipid content was then determined using the following equation according to Phillips et al. (1989):

Total lipid content $(\mathrm{g} / \mathrm{L})=($ total cholesterol $) \times 2.27+($ triglycerides $)$

$$
+62.3 \text {. }
$$

\subsection{Statistical analysis}

The statistical analyses were performed using Statistica 13 (TIBCO software Inc, United Kingdom) and RStudio (version 3.4.1; R Project for Statistical Computing). Statistical significance was set at $p<0.05$. Statistical analyses were performed on the 19 chemicals with detection frequencies (DF) $>40 \%$. We calculated the Spearman correlation coefficients between the concentrations of the 19 chemicals included in our analyses.

Two approaches were followed for the statistical exploration: monopollutant and multipollutant models. Our objective was to compare a classical monopollutant approach similar to those employed in Dufour et al. (2018) and an innovative multipollutant approach based on the use of the multiple imputation and the WQS methodology. Thereby, firstly, an individual logistical model was computed for each chemical, the outcome variable being the pathology status. On one hand, if the DF for the chemical was above $70 \%$, the xenobiotic concentrations (a natural logarithm transformation was applied to pollutant concentrations in order to satisfy the criteria of normality and measurements below the limit of quantification (LOQ) were replaced by LOQ $\times$ DF (Dufour et al., 2018)) were incorporated in the model. On the other hand, for pollutants with DF ranging between 40 and $70 \%$, the contamination status (detected vs. non-detected) was used for model calculation.

Secondly, to explore the associations between mixtures of pollutants and the thyroid pathology status, we used the multiple imputation in conjunction with WQS regression. The multiple imputation method was proposed by Lubin et al. (2004) to manage measurements below the LOQ. This method used a maximum likelihood algorithm to randomly select, from an appropriate distribution, values for the observations below the LOQ. Lubin et al. (2004) demonstrated that the multiple imputation method produces good parameter estimates unless the proportion of measurements below the LOQ is very high, we chose thus to limit our analyses on chemicals with DF $>40 \%$. Using this approach, we generated 5 complete sets of data and each dataset was analyzed using WQS regression. WQS models were computed according to the methodology proposed by Gennings et al. (2010) and improved by Carrico et al. (2015). The basic WQS model was as following:

$g(\mu)=\beta_{0}+\beta_{1}\left(\sum_{i=1}^{c} w_{i} q_{i}\right)+z^{\prime} \phi$

where $g(\mu)$ is the link function between the outcome variable and the predictor variables. $\beta_{0}$ is the intercept, $z$ ' is a vector of covariates and $\phi$ the vector of regression coefficients associated to these covariates. The term $\sum_{\mathrm{i}=1}^{\mathrm{c}} \mathrm{w}_{\mathrm{i}} \mathrm{q}_{\mathrm{i}}$ represents the WQS index, $\mathrm{c}$ is the number of chemicals included in the index, $\mathrm{q}_{\mathrm{i}}$ defines the score for the $i$ th component according to the quantile and $\mathrm{w}_{\mathrm{i}}$ is the weight attributed to the $i$ th chemical. The set of weights is computed using an optimization approach which maximizes the likelihood of the regression model. The weights are constrained to be positive and sum to one and are empirically estimated through the use of bootstrap samples. Finally, $\beta_{1}$ represents the regression coefficient for the WQS index and is constrained to be nonpositive or non-negative. For this analysis, the link function $g(\mu)$ was assumed to be a logit link because of the binary nature of the outcome variable (pathology status), the chemicals included in the WQS index were scored according to quartiles and $\mathrm{q}_{i}=0,1,2$, or 3 if the concentration value was in 1st, 2nd, 3rd and 4th quartile, respectively and 500 bootstrap samples were generated from our full data set to estimate the weights $\mathrm{w}_{\mathrm{i}}$. WQS models were constructed with $\beta_{1}$ constrained to be non-negative and additional models were computed with $\beta_{1}$ constrained to be non-positive to determine whether some pollutants were associated with reduced risk for thyroid pathologies (Deyssenroth et al., 2018). Finally, the parameters estimates computed with each imputed dataset were combined according the formula of Rubin (Rubin, 2004; Lubin et al., 2004). Two parameters are important for the interpretation of the WQS regression model. First, we considered the significance associated with $\beta_{1}$ to determinate whether there is an association between the WQS index and the thyroid pathology status. Second, we analyzed the index weights to identify "bad actors" which are the chemicals effectively associated with the outcome. For this analysis, pollutants associated with a weight above 0.075 were considered as bad actors (Carrico et al., 2015; Christensen et al., 2013; Czarnota et al., 2015). Monopollutant and multipollutant models were constructed for hypothyroidism and hyperthyroidism status separately but also, assuming that both pathologies are linked by a common immunopathological pathway (McLachlan et al., 2007), for any thyroid autoimmune disease status. All the models were adjusted for age, sex, smoking status, body mass index (BMI) and delay (in months) between sampling and start of the recruitment (to account for potential trend in measured POPs during the collection period). Additional models were computed (only for hypothyroidism and hyperthyroidism) in order to assess the robustness of our main observations: first, as PCB and organochlorine pesticide concentrations are usually adjusted for serum lipids, we created additional models including all the variables from the final models plus the total serum lipid levels (natural log transformed). Secondly, we reran final models by omitting the BMI in order to investigate the influence of this parameter. Thirdly, given the importance of the gender on the thyroid function and the prevalence of autoimmune thyroid diseases, we computed models by considering only female individuals. And finally, for both pathologies, we split chemicals into two groups: 
Table 1

Characteristic of cases and controls.

\begin{tabular}{|c|c|c|c|c|c|c|c|c|}
\hline & \multicolumn{4}{|c|}{ Cases } & \multicolumn{4}{|c|}{ Controls } \\
\hline & No & Mean & Range & $\%$ & No & Mean & Range & $\%$ \\
\hline Age, years & 78 & 43.8 & [17-74] & & & 44.1 & [19-71] & \\
\hline BMI, $\mathrm{kg} / \mathrm{m}^{2}$ & 77 & 25.1 & [17.5-45.8] & & & 24.9 & [16.3-37.6] & \\
\hline \multicolumn{9}{|l|}{ Sex } \\
\hline Male & 22 & & & $28.2 \%$ & 44 & & & $27.5 \%$ \\
\hline Female & 56 & & & $71.8 \%$ & 116 & & & $72.5 \%$ \\
\hline \multicolumn{9}{|l|}{ Smoking status } \\
\hline Smoker & 18 & & & $23.1 \%$ & 32 & & & $20.0 \%$ \\
\hline Non-smoker & 60 & & & $76.9 \%$ & 128 & & & $80.0 \%$ \\
\hline
\end{tabular}

those that were positively associated with the pathology (based on the OR computed in monopollutant model) and those that were negatively associated with the pathology. WQS index were computed for both group and the positive and the negative index were then combined in the same model, consequently, we computed one model with two WQS index for hypothyroidism and one model with two index for hyperthyroidism. Data imputation, WQS regression models and combination of the parameter estimates were computed using the $\mathrm{R}$ package miWQS (Hartgarten and Wheeler, 2018).

\section{Results}

Characteristics of the population were gathered in Table 1. As expected, the cases were mostly women (71.8\%). The mean age and BMI in the overall population were 44 years and $24.9 \mathrm{~kg} / \mathrm{m}^{2}$, respectively, and $21 \%$ of individuals were smoker. The DFs for the 54 POPs studied in this work were gathered in Table 2. Among these chemicals, 19 had DF above $40 \%$ and were thus included in the statistical analyses: 6 PFASs, 9 POHs, 1 organochlorine pesticide and 3 PCBs. The descriptive statistics for these chemicals are presented in Table 3. None of the BFRs was highlighted in more than $40 \%$ of the individuals and only PBDE 47 $(31.8 \%)$ and PBDE $153(38.5 \%)$ were measured in more than $20 \%$ of the population. Among PFASs, PFOS, PFOA, PFHxS and PFNA were highlighted in almost all the individuals with median concentrations of $3612,1600,805$ and $510 \mathrm{pg} / \mathrm{mL}$, respectively. Only the PFHpA was non-detected in most of the individuals. The DFs were also high for the chlorinated POHs namely the PCP and the OH-PCBs. PCP, 4-OH-CB 187, 4-OH-CB 107 and 4-OH-CB 146 were measured in the nearly entire population with median concentrations of $554,34.5,32.0$ and $29.2 \mathrm{pg} /$ $\mathrm{mL}$, respectively. The DFs for brominated POHs were largely lower except for 2,4,6-TBP (56.3\%) and to a lower extent TBBPA (38.7\%). Among organochlorine pesticides, 4,4'-DDE was determined in $50.4 \%$ of the individuals with a median concentration of $404.2 \mathrm{pg} / \mathrm{mL}$ and among the other pesticides, only $\beta-\mathrm{HCH}(39.1 \%)$ and $\mathrm{HCB}(37.4 \%)$ had DFs above $10 \%$. PCB 138 was measured in $45.4 \%$ of the individuals while PCB 153 and PCB 180 were detected in $92.0 \%$ and $89.5 \%$ of the population, respectively with respective median concentrations of 325 and $265 \mathrm{pg} / \mathrm{mL}$. DFs and median concentrations according to the disease status were gathered in supplemental materials Table S1. Except 2,4,6-TBP, chemicals were mostly significantly correlated with each other: 153 Spearman correlation coefficients out the 171 were significant. Significant coefficients ranged from 0.13 to 0.94 (supplemental materials Fig. S1).

The results of monopollutant analyses are gathered in Table 4. PFUdA, PFOA, PFNA, PFOS, PFDA and 3-OH-CB 138 were significantly associated with reduced odds of thyroid autoimmune diseases status while 4-OH-CB 146, 4,4'-DDE and PCB 138 were linked to increased odds of thyroid pathologies status. The profiles of the pollutants associated with hyperthyroidism or with hypothyroidism were different: higher contamination by PFHxS, PFOA, PFNA, PFOS, PFDA, 3-OH-CB 138 and 2,4,6-TBP were associated with reduced odds of hyperthyroidism while only PFOA, PFNA and PFDA were in relation with a reduction of the odds for hypothyroidism. On the other hand, 4-OH-CB 146, 4-OH-CB 172, РCB 180 and РСB 138 were linked to increased odds for this pathology, a borderline significant association was also highlighted with 4,4'-DDE.

The results of the WQS regression models are presented in Table 5. A quartile increase of the WQS index was associated with higher odds of having an autoimmune thyroid pathology (OR $=4.83 ; 95 \% \mathrm{CI}$ : 1.38-16.9) and hypothyroidism (OR $=98.1 ; 95 \%$ CI: 5.51-1747) but not with higher odds of suffering from hyperthyroidism (OR $=0.57$; 95\% CI: 0.11-2.99). WQS regressions were also performed to determine whether there were negative associations between the pollutant mixture and the different pathologies. WQS indexes were found to be significantly linked to reduced odds of autoimmune thyroid pathology $(\mathrm{OR}=0.17 ; 95 \% \mathrm{CI}: 0.06-0.46)$, hyperthyroidism (OR $=0.002 ; 95 \%$ CI: 0.00-0.09) and hypothyroidism (OR $=0.22$; 95\% CI: 0.06-0.77). Table 6 shows estimated pollutant weights for each significant WQS index. The most heavily weighted chemical for the positive association between mixture and any autoimmune thyroid diseases was 3-OH-CB $180(\mathrm{w}=0.249)$ followed by PCB $138(\mathrm{w}=0.190), 4,4^{\prime}-\mathrm{DDE}$ $(\mathrm{w}=0.180)$ and 4-OH-CB $146(\mathrm{w}=0.096)$. The weight index profile was similar for hypothyroidism and was dominated by PCB 138 $(\mathrm{w}=0.210), 3-$-OH-CB $180(\mathrm{w}=0.197), 4-\mathrm{OH}-\mathrm{CB} 146(\mathrm{w}=0.188)$ and $4,4^{\prime}$-DDE $(w=0.156)$. On the other hand, reduced odds of having an autoimmune thyroid pathology was associated with 3-OH-CB 138 $(\mathrm{w}=0.187)$, PFOA, $(\mathrm{w}=0.135)$, PFDA $(\mathrm{w}=0.128)$, PFUdA $(\mathrm{w}=0.110)$, PFOS $(\mathrm{w}=0.109)$, PFNA $(\mathrm{w}=0.108)$, PCP $(\mathrm{w}=0.080)$ and 2,4,6-TBP $(w=0.076)$. 3-OH-CB 138 was also heavily linked with reduced odds of hyperthyroidism $(w=0.395)$, the other chemicals with elevated weight were $2,4,6-\mathrm{TBP}(\mathrm{w}=0.141)$, PFDA $(\mathrm{w}=0.116)$ and PCP $(w=0.095)$. Finally, PFNA $(w=0.282)$, PFDA $(w=0.280)$ and PFOA ( $w=0.149$ ) had the highest weights in the WQS index associating chemical mixture and reduced odds of hypothyroidism.

Across sensitivity analyses, associations between WQS indexes and the thyroid disease prevalence remained stable and chemicals highlighted following the weights were identical when the models were additionally adjusted for total serum lipids (supplemental materials Tables S2 and S3). The observations were the same when BMI was omitted from the models, except that some additional chemicals received more important weight and were highlighted as linked to the pathology (e.g. PCB 180 for increased risk of hypothyroidism and PFHxS for decreased risk of hyperthyroidism) (supplemental materials Tables S2 and S4). Consequently our results seemed to be not significantly influenced by the total serum lipids or the BMI. Conversely, models restricted to female individuals provided slightly different results. Association between WQS index and increased risk for hypothyroidism remained significant while the link with reduced risk for hypothyroidism became insignificant (OR $=0.24$; 95\% CI: $0.04-1.43$ ) and those with reduced risk for hyperthyroidism became borderline $(\mathrm{OR}=0.03$; 95\% CI: 0.00-1.43). Chemicals selected according to weight were also slightly different with 4-OH-CB 107 additionally identified as linked with increased risk for hypothyroidism and PFOS and PFUdA linked to reduced risk for hyperthyroidism instead of PCP 
Table 2

Limits of quantification (LOQs) and detection frequencies (DFs) for all the chemicals assessed.

\begin{tabular}{|c|c|c|}
\hline & $\mathrm{LOQ}(\mathrm{pg} / \mathrm{mL})$ & DF (\%) \\
\hline \multicolumn{3}{|l|}{ PFASs } \\
\hline PFHрA & 50.0 & 25.3 \\
\hline PFHxS & 150.0 & 99.6 \\
\hline PFOA & 250.0 & 100.0 \\
\hline PFNA & 100.0 & 100.0 \\
\hline PFOS & 500.0 & 100.0 \\
\hline PFDA & 150.0 & 79.3 \\
\hline PFUdA & 100.0 & 69.2 \\
\hline \multicolumn{3}{|l|}{ BFRs } \\
\hline PBEB & 3.0 & 0.0 \\
\hline $\mathrm{HBBz}$ & 4.3 & 8.7 \\
\hline ЕНТВВ & 4.0 & 10.2 \\
\hline BTBPE & 5.7 & 17.4 \\
\hline PBB 153 & 4.2 & 0.0 \\
\hline PBDE 47 & 3.7 & 31.8 \\
\hline PBDE 99 & 5.3 & 2.6 \\
\hline PBDE 100 & 2.5 & 3.1 \\
\hline PBDE 153 & 4.2 & 38.5 \\
\hline PBDE 154 & 6.0 & 6.2 \\
\hline PBDE 183 & 3.8 & 15.4 \\
\hline PBDE 209 & 34.5 & 9.2 \\
\hline \multicolumn{3}{|l|}{$\mathrm{POHs}$} \\
\hline РCP & 44.6 & 98.3 \\
\hline TBBPA & 4.1 & 38.7 \\
\hline 5-OH-BDE 47 & 2.3 & 1.3 \\
\hline 6-OH-BDE 47 & 2.5 & 2.9 \\
\hline 5'-OH-BDE 99 & 2.2 & 2.9 \\
\hline 2,3,6-TBP & 2.4 & 2.1 \\
\hline $2,4,5-\mathrm{TBP}$ & 5.0 & 0.0 \\
\hline 2,4,6-ТВР & 49.6 & 56.3 \\
\hline 2,3,4,6-ТеВР & 4.1 & 16.4 \\
\hline 4-OH-СB 107 & 3.2 & 97.1 \\
\hline 3-ОН-СВ 138 & 3.1 & 86.1 \\
\hline 4-OH-CB 146 & 2.2 & 98.7 \\
\hline 3-OH-СB 153 & 3.0 & 67.6 \\
\hline 4-OH-CB 172 & 2.0 & 86.1 \\
\hline 3-OH-СB 180 & 2.1 & 60.1 \\
\hline 4-OH-СB 187 & 2.0 & 100.0 \\
\hline \multicolumn{3}{|l|}{ Organochlorine pesticides } \\
\hline$\alpha-\mathrm{HCH}$ & 50.0 & 0.8 \\
\hline$\beta-\mathrm{HCH}$ & 50.0 & 39.1 \\
\hline$\gamma-\mathrm{HCH}$ & 50.0 & 10.9 \\
\hline HCB & 80.0 & 37.4 \\
\hline Aldrine & 130.0 & 0.0 \\
\hline Oxychlordane & 200.0 & 1.3 \\
\hline trans-Heptachlor epoxide & 150.0 & 2.9 \\
\hline trans-Chlordane & 200.0 & 0.0 \\
\hline trans-Nonachlor & 60.0 & 8.4 \\
\hline cis-Nonachlor & 50.0 & 0.0 \\
\hline $4,4^{\prime}-\mathrm{DDE}$ & 400.0 & 50.4 \\
\hline $2,4^{\prime}-\mathrm{DDE}$ & 80.0 & 1.3 \\
\hline $2,4^{\prime}$-DDT & 410.0 & 0.4 \\
\hline Endrine & 500.0 & 0.0 \\
\hline Dieldrine & 200.0 & 1.3 \\
\hline$\beta$-Endosulfan & 50.0 & 0.4 \\
\hline \multicolumn{3}{|l|}{ PCBs } \\
\hline PCB 138 & 150.0 & 45.4 \\
\hline РCB 153 & 70.0 & 92.0 \\
\hline РCB 180 & 50.0 & 89.5 \\
\hline
\end{tabular}

and PFDA (supplemental materials Tables S2 and S5). Nevertheless, these changes may be the consequence of the reduction of the statistical power, models restricted to men would have been informative but, unfortunately, the number of male individuals was too low to perform statistical analyses. Regarding the models with positive and negative index combined (supplemental materials Table S6), chemicals associated with hypothyroidism were the same than those identified by regular models (PCB 138, 3-OH-CB 180, 4-OH-CB 146 and 4,4'-DDE positively associated with the pathology and PFNA, PFDA and PFOA negatively associated). On the other hand, unlike our initial model, model considering chemicals split in two groups highlighted a significant positive association with hyperthyroidism (OR $=84.1$; $95 \% \mathrm{CI}$ : 3.68-13588). The compounds highlighted as bad actors were 3-OH-CB 180, 4,4'-DDE and PCB 138. This methodology, called "grouped WQS", was proposed by Wheeler and Czarnota (2016) and seems to be informative when two groups of chemicals (one positively associated with the pathology and one negatively associated with the pathology) are present. Nevertheless, currently, this methodology is not fully described in the literature, consequently, it is actually difficult to discuss more extensively these results.

\section{Discussion}

We focused our investigations on autoimmune thyroid disorders. The first reason was that autoimmunity is the most common etiology for hypothyroidism and hyperthyroidism and is thus a major health concern. Secondly, several epidemiological studies showed positive associations between POP exposure and the presence of autoimmune thyroid antibodies (Turyk et al., 2008; Gaum et al., 2016). Another link between pollutants and thyroid autoimmunity was proposed by Webster et al. (2014). Based on their results, they established the "multiple hit hypothesis". This hypothesis suggests that individuals with multiple stressors to their thyroid function (e.g. autoimmune thyroid antibodies) may be more susceptible to thyroid disruption by pollutants.

Hashimoto's and Graves' diseases are two disorders linked to an autoimmune mechanism. Due to the potential immunotoxicity highlighted for some POPs (Langer et al., 2005), we hypothesized that an increased risk for both pathologies could be associated to a similar mixture of immunotoxic pollutants. We computed models for both disorders together. Nevertheless, our results showed that hypothyroidism and hyperthyroidism were associated with very different profiles of pollutants which suggests that the pathological pathways linking pollutants with both disorders were probably different in our population, and demonstrates that our models including both diseases were not relevant.

WQS regressions were used to assess the associations between autoimmune thyroid pathologies and mixtures of environmental POPs. These statistical models highlighted that an increase of the mixture index was associated with a higher odds of Hashimoto's hypothyroidism. In this index, PCB 138, 3-OH-CB 180, 4-OH-CB 146 and 4,4'DDE had the heaviest weights. Computed OR was surprisingly high (98.1), this could suggest that considering mixture effects reveals more significant association between exposure and pathologies. For instance, Lee et al. (2006) also highlighted very high ORs (up to 38.3) when assessing the association between a mixture of 6 POPs and the incidence of diabetes. Nevertheless, we cannot exclude that our results were affected by an unexpected bias or by inverse causality. Moreover, in the ideal use of WQS regression, study data are split into training dataset used to estimate the weights attributed to chemicals and validation dataset used to test the statistical significance. Given the relative low number of participants in our study, we chose not to split our dataset, consequently, our models were not validated and $p$ values should not be used for strict inferences but rather as a guide for representing strength of associations (Gennings et al., 2010). Nevertheless, we computed WQS models with training and validating datasets as sensitivity analyses (supplementary materials, Table S7). As expected, the statistical power of our analyses was reduced and none of the associations remained significant. However, it is interesting to observe that the odds ratio were much less extreme (for instance, $\mathrm{OR}=12$ versus $\mathrm{OR}=98$ for increased risk of hypothyroidism) which suggest that the non-optimal use of the WQS regression may result in overfitting of the coefficient estimates. Moreover, small sample size resulted in very imprecise estimates and large confidence intervals. Consequently, our results should be considered with caution and confirmed by larger scale studies. 
Table 3

Means, medians, ranges, percentiles 25, 75 and $95(\mathrm{pg} / \mathrm{mL})$ for the chemicals with detection frequency $>40 \%$.

\begin{tabular}{|c|c|c|c|c|c|c|c|}
\hline & Mean & Median & Min & Max & P25 & P75 & P95 \\
\hline PFHxS & 1013.0 & 805.0 & $<\mathrm{LOQ}$ & 7450.0 & 530.0 & 1340.0 & 2182.0 \\
\hline PFOA & 1873.2 & 1600.0 & 305.3 & 7094.0 & 1082.2 & 2310.0 & 4340.0 \\
\hline PFNA & 625.3 & 510.0 & 111.0 & 2580.0 & 360.0 & 800.0 & 1402.2 \\
\hline PFOS & 4384.0 & 3612.0 & 645.0 & 20565.0 & 2116.8 & 5450.0 & 11230.0 \\
\hline PFDA & 329.6 & 270.0 & $<\mathrm{LOQ}$ & 1320.0 & 171.0 & 390.0 & 830.0 \\
\hline PFUdA & 186.8 & 138.0 & $<\mathrm{LOQ}$ & 1019.0 & $<\mathrm{LOQ}$ & 230.0 & 530.0 \\
\hline PCP & 1324.2 & 554.2 & $<\mathrm{LOQ}$ & 35940.0 & $<$ LOQ & 1041.7 & 3582.0 \\
\hline 2,4,6-TBP & 74.6 & 53.3 & $<\mathrm{LOQ}$ & 1276.6 & $<\mathrm{LOQ}$ & 77.2 & 210.7 \\
\hline 4-OH-CB 107 & 52.2 & 32.0 & $<\mathrm{LOQ}$ & 361.8 & 18.8 & 63.3 & 173.0 \\
\hline 3-ОН-СВ 138 & 15.2 & 10.8 & $<\mathrm{LOQ}$ & 261.4 & 4.9 & 18.7 & 41.3 \\
\hline 4-ОН-СВ 146 & 40.2 & 29.2 & $<\mathrm{LOQ}$ & 228.9 & 17.0 & 50.2 & 111.0 \\
\hline 3-ОН-СВ 153 & 13.9 & 9.1 & $<\mathrm{LOQ}$ & 208.2 & $<\mathrm{LOQ}$ & 19.0 & 45.1 \\
\hline 4-OH-CB 172 & 10.4 & 7.2 & $<\mathrm{LOQ}$ & 50.6 & 3.3 & 14.1 & 28.3 \\
\hline 3-ОН-СВ 180 & 4.5 & 3.0 & $<\mathrm{LOQ}$ & 31.9 & $<\mathrm{LOQ}$ & 5.6 & 14.8 \\
\hline 4-ОН-СВ 187 & 40.6 & 34.5 & 6.5 & 182.4 & 22.2 & 51.7 & 85.6 \\
\hline $4,4^{\prime}-\mathrm{DDE}$ & 931.2 & 404.2 & $<\mathrm{LOQ}$ & 24700.2 & $<\mathrm{LOQ}$ & 837.5 & 3020.6 \\
\hline РСВ 138 & 182.3 & $<\mathrm{LOQ}$ & $<\mathrm{LOQ}$ & 1009.8 & $<\mathrm{LOQ}$ & 243.9 & 454.3 \\
\hline РСВ 153 & 405.7 & 325.8 & $<\mathrm{LOQ}$ & 2247.3 & 148.0 & 561.6 & 1023.7 \\
\hline РСB 180 & 329.6 & 265.3 & $<\mathrm{LOQ}$ & 1564.2 & 108.7 & 486.8 & 891.8 \\
\hline
\end{tabular}

The observation that one PCB and two metabolites of PCBs were positively associated with hypothyroidism was consistent with numerous studies published in the literature. In laboratory, many authors showed that PCBs reduced thyroxine $\left(\mathrm{T}_{4}\right)$ levels in exposed rats (Bansal and Zoeller, 2008; Crofton et al., 2005; Martin and Klaassen, 2010). The implication of OH-PCBs has been less studied, however, it may be preponderant. Indeed, these metabolites show higher structural similarities with THs because of the presence of the phenol function. Consequently, for instance, their binding capacities on transthyretin (a blood transport protein for THs) are several orders of magnitude higher than those of the native PCBs (Marchesini et al., 2008). Furthermore, Meerts et al. (2004) showed that OH-PCBs were also able to reduce $\mathrm{T}_{4}$ levels in rat. Several epidemiological studies also highlighted that high concentrations of PCBs were associated with reduced levels of thyroid hormones and/or increased levels of TSH in human populations (Abdelouahab et al., 2008; Benson et al., 2018; Gaum et al., 2016; Persky et al., 2001; Turyk et al., 2007) which is consistent with the clinical features of hypothyroidism. However, inverse associations have also been reported (Bloom et al., 2009; Eguchi et al., 2015). Moreover,
Table 5

Results from the multipollutant models assessing potential associations between the thyroid pathologies and the WQS index. Significant ORs are in bold. All the models were adjusted for age, sex, smoking status, body mass index and delay (in months) between sampling and start of the recruitment.

\begin{tabular}{llll}
\hline & OR & 95\% CI & $p$-value \\
\hline WQS increased risk for hypothyroidism & $\mathbf{9 8 . 1}$ & $\mathbf{( 5 . 5 1 - 1 7 4 7 )}$ & $\mathbf{0 . 0 0 2}$ \\
WQS reduced risk for hypothyroidism & $\mathbf{0 . 2 2}$ & $\mathbf{( 0 . 0 6 - 0 . 7 7 )}$ & $\mathbf{0 . 0 1 9}$ \\
WQS increased risk for hyperthyroidism & 0.57 & $(0.11-2.99)$ & 0.501 \\
WQS reduced risk for hyperthyroidism & $\mathbf{0 . 0 0 2}$ & $\mathbf{( 0 . 0 0 - 0 . 0 9 )}$ & $\mathbf{0 . 0 0 2}$ \\
WQS increased risk for any thyroid disease & $\mathbf{4 . 8 3}$ & $\mathbf{( 1 . 3 8 - 1 6 . 9 )}$ & $\mathbf{0 . 0 1 5}$ \\
WQS reduced risk for any thyroid disease & $\mathbf{0 . 1 7}$ & $\mathbf{( 0 . 0 6 - 0 . 4 6 )}$ & $<\mathbf{0 . 0 0 1}$ \\
\hline
\end{tabular}

studies exploring the association between PCB contamination and thyroid disorders failed to highlight significant link (Donato et al., 2008; Raffetti et al., 2018) but these studies did not focus on autoimmune thyroid disorders. Furthermore, in these studies, OH-PCBs were not measured while they could be important actors in the thyroid

Table 4

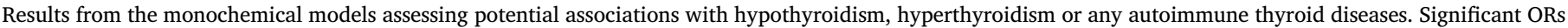
are in bold. All the models were adjusted for age, sex, smoking status, body mass index and delay (in months) between sampling and start of the recruitment.

\begin{tabular}{|c|c|c|c|c|c|c|}
\hline & \multicolumn{2}{|c|}{ Hypothyroidism } & \multicolumn{2}{|c|}{ Hyperthyroidism } & \multicolumn{2}{|c|}{ Any thyroid diseases } \\
\hline & OR & $95 \% \mathrm{CI}$ & OR & $95 \% \mathrm{CI}$ & OR & $95 \% \mathrm{CI}$ \\
\hline \multicolumn{7}{|l|}{ Continuous } \\
\hline Ln (PFHxS) & 0.78 & $(0.21-2.86)$ & 0.14 & $(0.03-0.63)$ & 0.47 & $(0.19-1.15)$ \\
\hline Ln (PFOA) & 0.18 & $(0.04-0.82)$ & 0.19 & $(0.05-0.74)$ & 0.23 & $(0.08-0.62)$ \\
\hline Ln (PFNA) & 0.19 & $(0.05-0.79)$ & 0.10 & $(0.02-0.45)$ & 0.17 & $(0.06-0.46)$ \\
\hline Ln (PFOS) & 0.43 & $(0.12-1.50)$ & 0.19 & $(0.06-0.64)$ & 0.32 & $(0.14-0.75)$ \\
\hline Ln (PFDA) & 0.19 & $(0.05-0.81)$ & 0.17 & $(0.05-0.57)$ & 0.24 & $(0.10-0.57)$ \\
\hline Ln (PCP) & 0.91 & $(0.55-1.53)$ & 0.84 & $(0.41-1.73)$ & 0.80 & $(0.53-1.22)$ \\
\hline Ln (4-OH-CB 107) & 1.43 & $(0.58-3.49)$ & 0.86 & $(0.35-2.11)$ & 0.94 & $(0.50-1.76)$ \\
\hline Ln (3-OH-CB 138) & 1.17 & $(0.40-3.45)$ & 0.10 & $(0.02-0.47)$ & 0.40 & $(0.18-0.90)$ \\
\hline Ln (4-OH-CB 146) & 13.7 & $(2.03-92.7)$ & 1.14 & $(0.37-3.56)$ & 2.61 & (1.13-6.04) \\
\hline Ln (4-OH-CB 172) & 4.95 & $(1.48-16.6)$ & 1.00 & $(0.56-1.78)$ & 1.84 & $(0.92-3.66)$ \\
\hline Ln (4-OH-CB 187) & 3.76 & $(0.55-25.5)$ & 0.32 & $(0.04-2.40)$ & 0.91 & $(0.25-3.32)$ \\
\hline Ln (PCB 153) & 1.34 & $(0.34-5.24)$ & 0.33 & $(0.08-1.47)$ & 0.63 & $(0.24-1.70)$ \\
\hline Ln (PCB 180) & 3.64 & (1.18-11.2) & 0.93 & $(0.27-3.24)$ & 1.83 & $(0.83-4.01)$ \\
\hline \multicolumn{7}{|l|}{ Binary } \\
\hline PFUdA (detected vs non-detected) & 0.30 & $(0.06-1.50)$ & 0.25 & $(0.04-1.52)$ & 0.30 & $(0.09-0.96)$ \\
\hline 2,4,6-TBP (detected vs non-detected) & 0.65 & $(0.16-2.72)$ & 0.20 & $(0.04-0.91)$ & 0.43 & $(0.16-1.18)$ \\
\hline 3-OH-СВ 153 (detected vs non-detected) & 1.51 & $(0.23-9.74)$ & 0.59 & $(0.10-3.39)$ & 1.06 & $(0.31-3.62)$ \\
\hline 3-OH-СВ 180 (detected vs non-detected) & 2.43 & $(0.48-12.3)$ & 3.37 & $(0.54-21.0)$ & 2.19 & $(0.63-7.60)$ \\
\hline $4,4^{\prime}$-DDE (detected vs non-detected) & 4.47 & $(0.96-20.8)$ & 1.83 & $(0.33-10.2)$ & 3.08 & $(1.02-9.35)$ \\
\hline PCB 138 (detected vs non-detected) & 8.88 & $(1.30-60.6)$ & 3.06 & $(0.60-15.5)$ & 4.63 & $(1.37-15.6)$ \\
\hline
\end{tabular}


Table 6

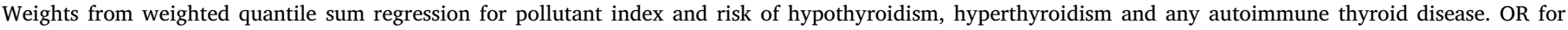
increased risk of hyperthyroidism was not significant, weights were thus not computed for this model. Weights above 0.075 are in bold.

\begin{tabular}{|c|c|c|c|c|c|c|c|c|c|}
\hline \multicolumn{2}{|c|}{ Increased risk for hypothyroidism } & \multicolumn{2}{|c|}{$\begin{array}{l}\text { Reduced risk for } \\
\text { hypothyroidism }\end{array}$} & \multicolumn{2}{|c|}{$\begin{array}{l}\text { Reduced risk for } \\
\text { hyperthyroidism }\end{array}$} & \multicolumn{2}{|c|}{$\begin{array}{l}\text { Increased risk for any thyroid } \\
\text { disease }\end{array}$} & \multicolumn{2}{|c|}{ Reduced risk for any thyroid disease } \\
\hline Chemical & Weight & Chemical & Weight & Chemical & Weight & Chemical & Weight & Chemical & Weight \\
\hline РСB 138 & 0.210 & PFNA & 0.282 & 3-OH-CB 138 & 0.395 & 3-OH-CB 180 & 0.249 & 3-OH-CB 138 & 0.187 \\
\hline 3-OH-CB 180 & 0.197 & PFDA & 0.280 & 2,4,6-ТВP & 0.141 & РСB 138 & 0.190 & PFOA & 0.135 \\
\hline 4-ОН-СВ 146 & 0.188 & PFOA & 0.149 & PFDA & 0.116 & 4,4'-DDE & 0.180 & PFDA & 0.128 \\
\hline 4,4'-DDE & 0.156 & РCP & 0.057 & PCP & 0.095 & 4-OH-CB 146 & 0.096 & PFUdA & 0.110 \\
\hline 4-OH-CB 172 & 0.062 & PFUdA & 0.054 & PFHxS & 0.070 & 4-OH-CB 107 & 0.066 & PFOS & 0.109 \\
\hline РCB 180 & 0.059 & PCB 153 & 0.040 & PFUdA & 0.048 & 4-OH-СB 172 & 0.051 & PFNA & 0.108 \\
\hline 4-OH-CB 107 & 0.043 & PFOS & 0.038 & PFOS & 0.043 & РСB 180 & 0.026 & PCP & 0.080 \\
\hline 3-OH-СB 153 & 0.024 & 2,4,6-ТВР & 0.037 & PFOA & 0.027 & 3-ОН-СВ 153 & 0.020 & 2,4,6-ТВР & 0.076 \\
\hline 2,4,6-ТBP & 0.022 & PFHxS & 0.024 & $4,4^{\prime}-\mathrm{DDE}$ & 0.024 & 2,4,6-ТВР & 0.015 & РCB 153 & 0.036 \\
\hline 3-OH-CB 138 & 0.019 & 3-OH-СB 180 & 0.006 & PFNA & 0.016 & 4-OH-CB 187 & 0.014 & PFHxS & 0.025 \\
\hline PCP & 0.007 & 3-ОН-СВ 153 & 0.004 & 3-ОН-СВ 153 & 0.004 & PCP & 0.012 & 4-OH-СB 172 & 0.003 \\
\hline 4-OH-CB 187 & 0.003 & 4-OH-CB 187 & 0.004 & 4-OH-CB 172 & 0.004 & PFHxS & 0.012 & 4-OH-CB 187 & 0.002 \\
\hline PFUdA & 0.002 & РCB 138 & 0.004 & РCB 153 & 0.003 & РCB 153 & 0.012 & PCB 138 & $<0.001$ \\
\hline РCB 153 & 0.002 & 3-ОH-СВ 138 & 0.003 & 4-OH-CB 187 & 0.003 & 3-ОН-СВ 138 & 0.011 & 3-ОH-СВ 153 & $<0.001$ \\
\hline PFHxS & 0.002 & РCB 180 & 0.003 & РСB 180 & 0.003 & PFOS & 0.010 & РCB 180 & $<0.001$ \\
\hline PFOS & 0.002 & 4-OH-CB 107 & 0.003 & 4-ОН-СВ 146 & 0.002 & PFUdA & 0.009 & 4-OH-СВ 146 & $<0.001$ \\
\hline PFOA & $<0.001$ & $4,4^{\prime}-\mathrm{DDE}$ & 0.003 & РCB 138 & 0.002 & PFOA & 0.009 & 3-OH-CB 180 & $<0.001$ \\
\hline PFDA & $<0.001$ & 4-OH-CB 172 & 0.003 & 4-ОН-СВ 107 & 0.002 & PFNA & 0.009 & $4,4^{\prime}-\mathrm{DDE}$ & $<0.001$ \\
\hline PFNA & $<0.001$ & 4-OH-CB 146 & 0.003 & 3-ОН-СВ 180 & 0.001 & PFDA & 0.008 & 4-OH-CB 107 & $<0.001$ \\
\hline
\end{tabular}

disruption by PCBs.

The presence of 4,4'-DDE among pollutants heavily weighted in the index related to hypothyroid is relatively consistent with the literature. Liu et al. (2015) observed a decrease of the thyroid hormone levels in rats exposed to a mixture of PCB 153 and 4,4'-DDE. Additionnally, our results are support the findings of Lopez-Espinosa et al. (2009). These authors reported a negative association between the 4,4'-DDE concentrations and the $T_{4}$ levels and a positive association between 4,4'DDE contamination and TSH levels in a cohort of pregnant women from Spain. Nevertheless, contradictory results have also been reported in some other epidemiological studies (Blanco-Muñoz et al., 2016; Meeker et al., 2007).

The association between a mixture of chemicals and reduced odds for hypothyroidism status was also studied. A significant correlation was highlighted with 3 PFASs, namely PFOA, PFNA and PFDA. This observation was not consistent with the literature because some investigations performed in laboratories showed that animals exposed to PFASs had reduced levels of thyroid hormones (Luebker et al., 2005; Martin et al., 2007). Moreover, several epidemiological studies have linked high levels of PFASs with higher incidence of thyroid disorders (Lopez-Espinosa et al., 2012; Melzer et al., 2010), but the PFAS contamination was 5-10 folds higher in these populations than in the present study.

Regarding WQS indexes computed for hyperthyroidism, 3 OH-CB 138, 2,4,6-TBP, PFDA and PCP were in relation with lower odds for hyperthyroidism while no index was associated with increased odds.

The present observation of a lower risk of hyperthyroidism associated with the pollutant mixture was consistent with several laboratory animal studies reporting lower TH levels in exposed animals than in controls (Bansal and Zoeller, 2008; Crofton et al., 2005; Liu et al., 2015; Luebker et al., 2005; Martin et al., 2007; Martin and Klaassen, 2010), but were inconsistent with the results of the epidemiological work carried out by Langer et al. (2007). Indeed, they highlighted an elevated number of individuals presenting subclinical hyperthyroidism among people highly exposed to PCBs in a Slovakian population. Given the case-control design of our investigation, we can suspect a reverse causality; hyperthyroid disease is associated with an accelerated metabolism, consequently the metabolization and the elimination of some POPs could be boosted in our hyperthyroid individuals which would have led to reduced levels of chemicals.

In this study, we performed the comparison of two approaches; a monopollutant approach where an individual statistical model was computed for each chemical, and a multipollutant approach where WQS regression was employed to consider all the compounds within a single model. When assessing the link between pollutants and reduced odds of hypothyroid, both approaches highlighted exactly the same compounds, but some divergences occurred when evaluating the associations with increased odds for hypothyroidism. On one hand, the multipollutant approach allowed to select two pollutant (3-OH-CB 180 and 4,4'-DDE) which would not have been identified using the individual statistical model, highlighting the importance of considering mixture effect. On the other hand, 4-OH-CB 172 and PCB 180 were not selected by the multipollutant approach, which suggests that the effect observed in the individual model might be due to the important correlations with 4-OH-CB 146 ( $r=0.82$ and $r=0.74$, respectively). Similar conclusions could be drawn for hyperthyroidsism, the multipollutant approach allowed the identification of an additional major actor (PCP) while some PFASs were dismissed meaning that the pairwise correlations between PFDA and all the other PFASs ( $\mathrm{r}$ ranging between 0.43 and 0.87 ) resulted in the artifactual highlighting of several PFASs in the monochemical statistics. In comparison with the monopollutant analysis, WQS regression seemed to be more sensitive in identifying chemicals that were not selected in monopollutant approach and more convenient in order to reveal the true bad actors among groups of highly intercorrelated chemicals (Carrico et al., 2015; Czarnota et al., 2015). The method for selecting a reasonable threshold to identify bad actors is still under research (Czarnota et al., 2015), the inverse of the number of chemicals (in this study: $1 / 19=0.053$ ) may be an appropriate choice, nevertheless we chose a higher threshold (0.075) in order to promote specificity, obviously, the sensitivity was consequently reduced and some additional pollutants could have been selected with a more permissive threshold.

However, the WQS methodology is not without limitations. WQS model is only able to explore the mixture effect in one direction. Thus, the chemicals with opposite effects cannot be assessed in the same model. Moreover, using WQS regression implied that the effect is linear and that there is no interaction among the compounds incorporated into the index, WQS is thus not suitable to study non-monotonic exposure-outcome curves or synergistic or antagonist effects (Carrico et al., 2015). Notwithstanding these limitations, WQS regression represents an important step forward the understanding on how mixtures of POPs can interfere with the thyroid system in human. Another 
strength of this study was the assessment of 54 chemicals in a human population. Among them, 19 were highlighted in more than $40 \%$ of the individuals and could thus be incorporated in the statistical analyses. Unfortunately none of the BFRs measured had a sufficient DF to be included into the statistical models, but that means that BFR contamination in Belgium was limited and thus the influence of these chemicals on thyroid function could be less significant regarding the other chemicals assessed. Conversely, 9 POHs among the 16 assessed were highlighted in most of the participants and were thus included in the statistical analyses. The associations between POHs and human thyroid function were rarely assessed in epidemiological studies. However, POHs were measured in several populations worldwide (Dufour et al., 2017) and, as mentioned above for OH-PCBs, they are suspected to be potent thyroid disruptors, in particular by presenting a high affinity for the transthyretin (Cheek et al., 1999; Hamers et al., 2006; Marchesini et al., 2008). Investigations exploring the link between $\mathrm{POH}$ exposure and thyroid disruption should thus be encouraged.

However, our work suffered from several limitations. Given the case-control design of our investigation, we may be subject to a reverse causality since lower concentrations observed for several chemicals in hyperthyroid patient could be the consequence of an accelerated metabolism. Moreover, the positive correlation observed between some POPs and hypothyroidism could be the result of the slowed metabolism characteristic of a reduced thyroid function. To definitely establish the etiology direction, prospective studies assessing associations between mixtures of pollutants and thyroid disorder incidence should be performed in the future. Moreover, because most of the case participants were under treatment at the enrollment in our study, their TH levels were thus stabilized and consequently, we could not assess the correlations between the POP contamination and the levels of THs. Longitudinal investigations should allowed to explore relation between exposure to a mixture of POPs and TH levels.

Another limitation of our work is the relative low number of individuals which decreased the statistical power of the analyses and prevented the use of advanced analyses, for instance, by stratifying models by sex (we performed analyses for women, but the number of male individuals was too low to compute analyses restricted to men) or by age groups or by splitting our data into training and validation datasets. Given this limitation, we should consider the present study as a preliminary, hypothesis-generating investigation. Moreover, the recruitment of the population from which the controls originated was not originally designed for the purpose of this study but in order to be representative of the general population. Thyroid pathology status is thus unknown for a large proportion of these individuals especially since we did not assess the presence of thyroid peroxidase antibodies or TSHreceptor antibodies in our control cohort. Thus, we could not be certain that our control cohort did not include individuals with thyroid disorder. Nevertheless, given the prevalence of overt hypo- and hyperthyroidism in Europe (1-2\% for combined pathologies, Garmendia Madariaga et al., 2014), the potential bias seemed to us acceptable. Moreover, according to the "multiple hit hypothesis" of Webster et al. (2014), it would have been interesting to make a comparison between mixture of pollutants measured in the thyroid patients and in individuals with thyroid antibodies but not diagnosed for thyroid disorders. Other potential important confounding factors as blood selenium, iodine status or blood lipids were not controlled. These variables should be included on future larger scale studies in order to improve result confidence. Finally, our analyses involved 5 POP families which are considered as potential thyroid disruptors (Boas et al., 2012), but some other chemicals such as phthalates, bisphenol A, and UV-filters are also suspected to be thyroid disruptors (Boas et al., 2012) and could have been included in our investigations. However, these chemicals are non-persistent pollutants and their concentrations measured in one urine sample may be not representative of the long-term exposure. To accurately assess the exposure to these pollutants in human population for epidemiological studies is certainly a major challenge for the future.

\section{Acknowledgments}

We would like to thank the physicians of the Department of Endocrinology of the University Hospital of Liege for their collaboration in the recruitment of volunteers. We also want to thank all the volunteers who kindly participated to the study. Finally, we express our gratitude to the Department Clinical Chemistry of the University Hospital of Liege for their assistance for the lipids determination.

\section{Appendix A. Supplementary data}

Supplementary data to this article can be found online at https:// doi.org/10.1016/j.envres.2019.108922.

\section{Funding sources}

This research did not receive any specific grant from funding agencies in the public, commercial, or not-for-profit sectors.

\section{References}

Abdelouahab, N., Mergler, D., Takser, L., Vanier, C., St-Jean, M., Baldwin, M., Spear, P.A., Chan, H.M., 2008. Gender differences in the effects of organochlorines, mercury, and lead on thyroid hormone levels in lakeside communities of Quebec (Canada). Environ. Res. 107, 380-392. https://doi.org/10.1016/j.envres.2008.01.006.

Bansal, R., Zoeller, R.T., 2008. Polychlorinated biphenyls (Aroclor 1254) do not uniformly produce agonist actions on thyroid hormone responses in the developing rat brain. Endocrinology 149, 4001-4008. https://doi.org/10.1210/en.2007-1774.

Benson, K., Yang, E., Dutton, N., Sjodin, A., Rosenbaum, P.F., Pavuk, M., 2018. Polychlorinated biphenyls, indicators of thyroid function and thyroid autoantibodies in the Anniston Community Health Survey I (ACHS-I). Chemosphere 195, 156-165. https://doi.org/10.1016/j.chemosphere.2017.12.050.

Benvenga, S., Antonelli, A., Vita, R., 2015. Thyroid nodules and thyroid autoimmunity in the context of environmental pollution. Rev. Endocr. Metab. Disord. 16, 319-340. https://doi.org/10.1007/s11154-016-9327-6.

Berg, V., Nøst, T.H., Pettersen, R.D., Hansen, S., Veyhe, A.-S., Jorde, R., Odland, J.Ø., Sandanger, T.M., 2017. Persistent organic pollutants and the association with maternal and infant thyroid homeostasis: a multipollutant assessment. Environ Health Perspect 125, 127-133. https://doi.org/10.1289/EHP152.

Billionnet, C., Sherrill, D., Annesi-Maesano, I., 2012. Estimating the health effects of exposure to multi-pollutant mixture. Ann. Epidemiol. 22, 126-141. https://doi.org/ 10.1016/j.annepidem.2011.11.004.

Blanco-Muñoz, J., Lacasaña, M., López-Flores, I., Rodríguez-Barranco, M., GonzálezAlzaga, B., Bassol, S., Cebrian, M.E., López-Carrillo, L., Aguilar-Garduño, C., 2016 Association between organochlorine pesticide exposure and thyroid hormones in floriculture workers. Environ. Res. 150, 357-363. https://doi.org/10.1016/j.envres. 2016.05.054.

Bloom, M.S., Vena, J.E., Olson, J.R., Kostyniak, P.J., 2009. Assessment of polychlorinated biphenyl congeners, thyroid stimulating hormone, and free thyroxine among New York State anglers. Int. J. Hyg Environ. Health 212, 599-611. https://doi.org/10. 1016/j.ijheh.2009.04.005.

Boas, M., Feldt-Rasmussen, U., Main, K.M., 2012. Thyroid effects of endocrine disrupting chemicals. Molecular and Cellular Endocrinology. Health Impacts Of Endocrine DisrupHealth Impacts Of Endocr Disruptersters 355, 240-248. https://doi.org/10. 1016/j.mce.2011.09.005.

Carrico, C., Gennings, C., Wheeler, D.C., Factor-Litvak, P., 2015. Characterization of weighted quantile sum regression for highly correlated data in a risk analysis setting. Journal of agricultural. Biol Environ Stat 20, 100-120. https://doi.org/10.1007/ s13253-014-0180-3.

Cheek, A.O., Kow, K., Chen, J., McLachlan, J.A., 1999. Potential mechanisms of thyroid disruption in humans: interaction of organochlorine compounds with thyroid receptor, transthyretin, and thyroid-binding globulin. Environ. Health Perspect. 107, 273-278. https://doi.org/10.1289/ehp.99107273.

Chen, H., Liu, Z., Zhang, X., Jia, X., Li, Q., Su, Q., Wang, W., 2016. Assessment of synergistic thyroid disrupting effects of a mixture of EDCs in ovariectomized rats using factorial analysis and dose addition. Toxicol Res (Cambridge) 5, 1585-1593. https:// doi.org/10.1039/c6tx00193a.

Chevrier, J., Harley, K.G., Bradman, A., Gharbi, M., Sjödin, A., Eskenazi, B., 2010. Polybrominated diphenyl ether (PBDE) flame retardants and thyroid hormone during pregnancy. Environ. Health Perspect. 118, 1444-1449. https://doi.org/10.1289/ehp. 1001905.

Christensen, K.L., Carr, C., Sanyal, A.J., Gennings, C., 2013. Multiple classes of environmental chemicals are associated with liver disease: nhanes 2003-2004. Int. J. Hyg Environ. Health 216, 703-709. https://doi.org/10.1016/j.ijheh.2013.01.005.

Crofton, K.M., Craft, E.S., Hedge, J.M., Gennings, C., Simmons, J.E., Carchman, R.A., Carter, W.H., DeVito, M.J., 2005. Thyroid-hormone-disrupting chemicals: evidence for dose-dependent additivity or synergism. Environ Health Perspect 113, 1549-1554. https://doi.org/10.1289/ehp.8195.

Czarnota, J., Gennings, C., Wheeler, D.C., 2015. Assessment of weighted quantile sum 
regression for modeling chemical mixtures and cancer risk. Canc. Inf. 14, 159-171. https://doi.org/10.4137/CIN.S17295.

Deyssenroth, M.A., Gennings, C., Liu, S.H., Peng, S., Hao, K., Lambertini, L., Jackson, B.P., Karagas, M.R., Marsit, C.J., Chen, J., 2018. Intrauterine multi-metal exposure is associated with reduced fetal growth through modulation of the placental gene network. Environ. Int. 120, 373-381. https://doi.org/10.1016/j.envint.2018.08.010.

Donato, F., Zani, C., Magoni, M., Gelatti, U., Covolo, L., Orizio, G., Speziani, F., Indelicato, A., Scarcella, C., Bergonzi, R., Apostoli, P., 2008. Polychlorinated biphenyls and thyroid hormone serum concentrations among people living in a highly polluted area: a cross-sectional population-based study. Environ. Res. 108, 380-386. https://doi. org/10.1016/j.envres.2008.08.003.

Dufour, P., Pirard, C., Charlier, C., 2017. Determination of phenolic organohalogens in human serum from a Belgian population and assessment of parameters affecting the human contamination. Sci. Total Environ. 599-600, 1856-1866. https://doi.org/10. 1016/j.scitotenv.2017.05.157.

Dufour, P., Pirard, C., Charlier, C., 2016. Validation of a novel and rapid method for the simultaneous determination of some phenolic organohalogens in human serum by GC-MS. J. Chromatogr. B 1036-1037, 66-75. https://doi.org/10.1016/j.jchromb. 2016.10.002.

Dufour, P., Pirard, C., Seghaye, M.-C., Charlier, C., 2018. Association between organohalogenated pollutants in cord blood and thyroid function in newborns and mothers from Belgian population. Environ. Pollut. 238, 389-396. https://doi.org/10.1016/j. envpol.2018.03.058.

Eguchi, A., Nomiyama, K., Minh Tue, N., Trang, P.T.K., Hung Viet, P., Takahashi, S., Tanabe, S., 2015. Residue profiles of organohalogen compounds in human serum from e-waste recycling sites in North Vietnam: association with thyroid hormone levels. Environ. Res. 137, 440-449. https://doi.org/10.1016/j.envres.2015.01.007.

Faust, M., Altenburger, R., Backhaus, T., Blanck, H., Boedeker, W., Gramatica, P., Hamer, V., Scholze, M., Vighi, M., Grimme, L.H., 2001. Predicting the joint algal toxicity of multi-component s-triazine mixtures at low-effect concentrations of individual toxicants. Aquat. Toxicol. 56, 13-32. https://doi.org/10.1016/S0166-445X(01)00187-4.

Garmendia Madariaga, A., Santos Palacios, S., Guillén-Grima, F., Galofré, J.C., 2014. The incidence and prevalence of thyroid dysfunction in Europe: a meta-analysis. J. Clin. Endocrinol. Metab. 99, 923-931. https://doi.org/10.1210/jc. 2013-2409.

Gaum, P.M., Lang, J., Esser, A., Schettgen, T., Neulen, J., Kraus, T., Gube, M., 2016. Exposure to polychlorinated biphenyls and the thyroid gland - examining and discussing possible longitudinal health effects in humans. Environ. Res. 148, 112-121. https://doi.org/10.1016/j.envres.2016.03.022.

Gennings, C., Sabo, R., Carney, E., 2010. Identifying subsets of complex mixtures most associated with complex diseases: polychlorinated biphenyls and endometriosis as a case study. Epidemiology 21 (Suppl. 4), S77-S84. https://doi.org/10.1097/EDE. 0b013e3181ce946c.

Hamers, T., Kamstra, J.H., Sonneveld, E., Murk, A.J., Kester, M.H.A., Andersson, P.L., Legler, J., Brouwer, A., 2006. In vitro profiling of the endocrine-disrupting potency of brominated flame retardants. Toxicol. Sci. 92, 157-173. https://doi.org/10.1093/ toxsci/kfj187.

Hartgarten, P., Wheeler, D., 2018. miWQS: Multiple Imputation Using Weighted Quantile Sum Analysis.

Hass, U., Scholze, M., Christiansen, S., Dalgaard, M., Vinggaard, A.M., Axelstad, M., Metzdorff, S.B., Kortenkamp, A., 2007. Combined exposure to anti-androgens exacerbates disruption of sexual differentiation in the rat. Environ Health Perspect 115 (Suppl. 1), 122-128. https://doi.org/10.1289/ehp.9360.

Hermens, J., Leeuwangh, P., Musch, A., 1985. Joint toxicity of mixtures of groups of organic aquatic pollutants to the guppy (Poecilia reticulata). Ecotoxicol. Environ. Saf. 9, 321-326. https://doi.org/10.1016/0147-6513(85)90049-1.

Kärrman, A., Ericson, I., van Bavel, B., Darnerud, P.O., Aune, M., Glynn, A., Lignell, S., Lindström, G., 2007. Exposure of perfluorinated chemicals through lactation: levels of matched human milk and serum and a temporal trend, 1996-2004, in Sweden. Environ Health Perspect 115, 226-230. https://doi.org/10.1289/ehp. 9491.

Kortenkamp, A., 2014. Low dose mixture effects of endocrine disrupters and their implications for regulatory thresholds in chemical risk assessment. Current Opinion in Pharmacology, Gastrointestinal. Endocr Metab Dis. 19, 105-111. https://doi.org/10. 1016/j.coph.2014.08.006

Kortenkamp, A., 2007. Ten years of mixing cocktails: a review of combination effects of endocrine-disrupting chemicals. Environ Health Perspect 115 (Suppl. 1), 98-105. https://doi.org/10.1289/ehp.9357.

Kortenkamp, A., Faust, M., 2018. Regulate to reduce chemical mixture risk. Science 361, 224-226. https://doi.org/10.1126/science.aat9219.

Langer, P., Kocan, A., Tajtakova, M., Petrik, J., Chovancova, J., Drobna, B., Jursa, S., Pavuk, M., Trnovec, T., Seböková, E., Klimes, I., 2005. Human thyroid in the population exposed to high environmental pollution by organochlorinated pollutants for several decades. Endocr. Regul. 39, 13-20. https://doi.org/10.1097/01.jom. 0000058346.05741.b0.

Langer, P., Kočan, A., Tajtáková, M., Rádiková, Ž., Petrík, J., Koška, J., Kšinantová, L., Imrich, R., Hučková, M., Chovancová, J., Drobná, B., Jursa, S., Bergman, A., Athanasiadou, M., Hovander, L., Gašperíková, D., Trnovec, T., Šeböková, E., Klimeš, I., 2007. Possible effects of persistent organochlorinated pollutants cocktail on thyroid hormone levels and pituitary-thyroid interrelations. Chemosphere 70 , 110-118. https://doi.org/10.1016/j.chemosphere.2007.06.046.

Lee, D.-H., Lee, I.-K., Song, K., Steffes, M., Toscano, W., Baker, B.A., Jacobs, D.R., 2006. A strong dose-response relation between serum concentrations of persistent organic pollutants and diabetes results from the national health and examination survey 1999-2002. Diabetes Care 29, 1638-1644. https://doi.org/10.2337/dc06-0543.

Leese, G.P., Flynn, R.V., Jung, R.T., Macdonald, T.M., Murphy, M.J., Morris, A.D., 2008. Increasing prevalence and incidence of thyroid disease in tayside, scotland: the thyroid epidemiology audit and research study (TEARS). Clin. Endocrinol. 68,
311-316. https://doi.org/10.1111/j.1365-2265.2007.03051.x.

Lind, P., Langsteger, W., Molnar, M., Gallowitsch, H.J., Mikosch, P., Gomez, I. 1998. Epidemiology of thyroid diseases in iodine sufficiency. Thyroid 8, 1179-1183. https://doi.org/10.1089/thy.1998.8.1179.

Liu, C., Li, L., Ha, M., Qi, S., Duan, P., Yang, K., 2015. The PI3K/Akt and ERK pathways elevate thyroid hormone receptor $\beta 1$ and TRH receptor to decrease thyroid hormones after exposure to PCB153 and p,p'-DDE. Chemosphere 118, 229-238. https://doi. org/10.1016/j.chemosphere.2014.09.023.

Lopez-Espinosa, M.-J., Mondal, D., Armstrong, B., Bloom, M.S., Fletcher, T., 2012. Thyroid function and perfluoroalkyl acids in children living near a chemical plant. Environ Health Perspect 120, 1036-1041. https://doi.org/10.1289/ehp.1104370.

Lopez-Espinosa, M.-J., Vizcaino, E., Murcia, M., Llop, S., Espada, M., Seco, V., Marco, A., Rebagliato, M., Grimalt, J.O., Ballester, F., 2009. Association between thyroid hormone levels and 4,4'-DDE concentrations in pregnant women (Valencia, Spain). Environ. Res. 109, 479-485. https://doi.org/10.1016/j.envres.2009.02.003.

Lubin, J.H., Colt, J.S., Camann, D., Davis, S., Cerhan, J.R., Severson, R.K., Bernstein, L., Hartge, P., 2004. Epidemiologic evaluation of measurement data in the presence of detection limits. Environ Health Perspect 112, 1691-1696. https://doi.org/10.1289/ ehp.7199.

Luebker, D.J., York, R.G., Hansen, K.J., Moore, J.A., Butenhoff, J.L., 2005. Neonatal mortality from in utero exposure to perfluorooctanesulfonate (PFOS) in SpragueDawley rats: dose-response, and biochemical and pharamacokinetic parameters. Toxicology 215, 149-169. https://doi.org/10.1016/j.tox.2005.07.019.

Marchesini, G.R., Meimaridou, A., Haasnoot, W., Meulenberg, E., Albertus, F., Mizuguchi, M., Takeuchi, M., Irth, H., Murk, A.J., 2008. Biosensor discovery of thyroxine transport disrupting chemicals. Toxicol. Appl. Pharmacol. 232, 150-160. https://doi. org/10.1016/j.taap.2008.06.014.

Martin, L., Klaassen, C.D., 2010. Differential effects of polychlorinated biphenyl congeners on serum thyroid hormone levels in rats. Toxicol. Sci. 117, 36-44. https://doi. org/10.1093/toxsci/kfq187.

Martin, M.T., Brennan, R.J., Hu, W., Ayanoglu, E., Lau, C., Ren, H., Wood, C.R., Corton, J.C., Kavlock, R.J., Dix, D.J., 2007. Toxicogenomic study of triazole fungicides and perfluoroalkyl acids in rat livers predicts toxicity and categorizes chemicals based on mechanisms of toxicity. Toxicol. Sci. 97, 595-613. https://doi.org/10.1093/toxsci/ kfm065.

Martin, O.V., Martin, S., Kortenkamp, A., 2013. Dispelling urban myths about default uncertainty factors in chemical risk assessment - sufficient protection against mixture effects? Environ. Health 12 (53). https://doi.org/10.1186/1476-069X-12-53.

McGrogan, A., Seaman, H.E., Wright, J.W., De Vries, C.S., 2008. The incidence of autoimmune thyroid disease: a systematic review of the literature. Clin. Endocrinol. 69, 687-696. https://doi.org/10.1111/j.1365-2265.2008.03338.x.

McLachlan, S.M., Nagayama, Y., Pichurin, P.N., Mizutori, Y., Chen, C.-R., Misharin, A., Aliesky, H.A., Rapoport, B., 2007. The link between Graves' disease and Hashimoto's thyroiditis: a role for regulatory T cells. Endocrinology 148, 5724-5733. https://doi. org/10.1210/en.2007-1024.

McLeod, D.S.A., Cooper, D.S., 2012. The incidence and prevalence of thyroid autoimmunity. Endocrine 42, 252-265. https://doi.org/10.1007/s12020-012-9703-2.

Meeker, J.D., Altshul, L., Hauser, R., 2007. Serum PCBs, p,p'-DDE and HCB predict thyroid hormone levels in men. Environ. Res. 104, 296-304. https://doi.org/10. 1016/j.envres.2006.11.007.

Meerts, I.A.T.M., Lilienthal, H., Hoving, S., Berg, van den, J.H.J., Weijers, B.M., Bergman, Å., Koeman, J.H., Brouwer, A., 2004. Developmental exposure to 4-hydroxy2,3,3', 4',5-pentachlorobiphenyl (4-OH-cb107): long-term effects on brain development, behavior, and brain stem auditory evoked potentials in rats. Toxicol. Sci. 82, 207-218. https://doi.org/10.1093/toxsci/kfh252.

Melzer, D., Rice, N., Depledge, M.H., Henley, W.E., Galloway, T.S., 2010. Association between serum perfluorooctanoic acid (PFOA) and thyroid disease in the U.S National Health and Nutrition Examination Survey. Environ Health Perspect 118, 686-692. https://doi.org/10.1289/ehp.0901584.

Miller, V.M., Sanchez-Morrissey, S., Brosch, K.O., Seegal, R.F., 2012. Developmental coexposure to polychlorinated biphenyls and polybrominated diphenyl ethers has additive effects on circulating thyroxine levels in rats. Toxicol. Sci. 127, 76-83. https:// doi.org/10.1093/toxsci/kfs089.

Oulhote, Y., Chevrier, J., Bouchard, M.F., 2016. Exposure to polybrominated diphenyl ethers (PBDEs) and hypothyroidism in Canadian women. J. Clin. Endocrinol. Metab. 101, 590-598. https://doi.org/10.1210/jc.2015-2659.

Persky, V., Turyk, M., Anderson, H.A., Hanrahan, L.P., Falk, C., Steenport, D.N., Chatterton, R., Freels, S., Great Lakes Consortium, 2001. The effects of PCB exposure and fish consumption on endogenous hormones. Environ Health Perspect 109, 1275-1283. https://doi.org/10.1289/ehp.011091275.

Pirard, C., Charlier, C., 2018. Simple and fast method for the measurement of legacy and novel brominated flame retardants in human serum. Chemosphere 211, 918-925. https://doi.org/10.1016/j.chemosphere.2018.08.012.

Pirard, C., Compere, S., Firquet, K., Charlier, C., 2018. The current environmental levels of endocrine disruptors (mercury, cadmium, organochlorine pesticides and PCBs) in a Belgian adult population and their predictors of exposure. Int. J. Hyg Environ. Health 221, 211-222. https://doi.org/10.1016/j.ijheh.2017.10.010.

Raffetti, E., Donato, F., Speziani, F., Scarcella, C., Gaia, A., Magoni, M., 2018 Polychlorinated biphenyls (PCBs) exposure and cardiovascular, endocrine and metabolic diseases: a population-based cohort study in a North Italian highly polluted area. Environ. Int. 120, 215-222. https://doi.org/10.1016/j.envint.2018.08.022.

Rizzo, M., Rossi, R.T., Bonaffini, O., Scisca, C., Altavilla, G., Calbo, L., Rosanò, A., Sindoni, A., Trimarchi, F., Benvenga, S., 2010. Increased annual frequency of Hashimoto's thyroiditis between years 1988 and 2007 at a cytological unit of Sicily. Ann. Endocrinol. 71, 525-534. https://doi.org/10.1016/j.ando.2010.06.006.

Rubin, D.B., 2004. Multiple Imputation for Nonresponse in Surveys. John Wiley \& Sons. 
Schell, L.M., Gallo, M.V., Ravenscroft, J., DeCaprio, A.P., 2009. Persistent organic pollutants and anti-thyroid peroxidase levels in Akwesasne Mohawk young adults. Environ. Res. 109, 86-92. https://doi.org/10.1016/j.envres.2008.08.015.

Silva, E., Rajapakse, N., Kortenkamp, A., 2002. Something from "nothing"-eight weak estrogenic chemicals combined at concentrations below NOECs produce significant mixture effects. Environ. Sci. Technol. 36, 1751-1756. https://doi.org/10.1021/ es0101227.

Turyk, M.E., Anderson, H.A., Persky, V.W., 2007. Relationships of thyroid hormones with polychlorinated biphenyls, dioxins, furans, and DDE in adults. Environ Health Perspect 115, 1197-1203. https://doi.org/10.1289/ehp.10179.

Turyk, M.E., Persky, V.W., Imm, P., Knobeloch, L., Chatterton, R., Anderson, H.A., 2008. Hormone disruption by PBDEs in adult male sport fish consumers. Environ Health Perspect 116, 1635-1641. https://doi.org/10.1289/ehp.11707.

Villa, S., Migliorati, S., Monti, G.S., Vighi, M., 2012. Toxicity on the luminescent bacterium Vibrio fischeri (Beijerinck). II: response to complex mixtures of heterogeneous chemicals at low levels of individual components. Ecotoxicol. Environ. Saf. 86, 93-100. https://doi.org/10.1016/j.ecoenv.2012.08.030.

Webster, G.M., Venners, S.A., Mattman, A., Martin, J.W., 2014. Associations between Perfluoroalkyl acids (PFASs) and maternal thyroid hormones in early pregnancy: a population-based cohort study. Environ. Res. 133, 338-347. https://doi.org/10. 1016/j.envres.2014.06.012.

Wheeler, D., Czarnota, J., 2016. Modeling Chemical Mixture Effects with Grouped Weighted Quantile Sum Regression. ISEE 2016. https://doi.org/10.1289/isee.2016. 4698. Rome, Italy (September 1).

Yard, E.E., Terrell, M.L., Hunt, D.R., Cameron, L.L., Small, C.M., McGeehin, M.A., Marcus, M., 2011. Incidence of thyroid disease following exposure to polybrominated biphenyls and polychlorinated biphenyls, Michigan, 1974-2006. Chemosphere 84, 863-868. https://doi.org/10.1016/j.chemosphere.2011.06.020. 